\title{
ANALISIS PELAKSANAAN PROGRAM SISTEM JAMINAN KESEHATAN NASIONAL (JKN) DI PUSKESMAS SINDAR RAYA KABUPATEN SIMALUNGUN
}

\author{
${ }^{1}$ Pinondang Hotria Siregar, ${ }^{2}$ Ricard Fredrik Marpaung, ${ }^{3}$ Deswidya Sukrisna Hutauruk \\ ${ }^{1}$ Program Studi Sarjana Ilmu Kesehatan Masyarakat, Fakultas Kesehatan, Universitas Efarina \\ ${ }^{2}$ Program Studi Sarjana Keperawatan, Fakultas Kesehatan, Universitas Efarina \\ ${ }^{3}$ Program Studi Diploma III Analisis Kesehatan, Fakultas Kesehatan, Universitas Efarina \\ Email : ${ }^{1}$ pinria85@gmail.com, ${ }^{2}$ ricardfredrik.marpaung@yahoo.co.id, \\ ${ }^{3}$ sukrisna.hutauruk@gmail.com
}

\begin{abstract}
ABSTRAK
Sumber daya manusia Puskesmas Sindar Raya masih kurang secara kuantitas dan kualitas. Namun dalam pelayanan kesehatan, tidak ada perbedaan secara mendasar dengan pelayanan sebelum JKN dengan era $J K N$. Kemampuan administrasi sumber daya masih kurang siap dalam menerapkan format pelaporan JKN. Sarana dan prasarana masih tergolong kurang namun masih bisa memaksimalkan pelayanan kesehatan kepada masyarakat. Sarana medis yang masih belum lengkap adalah pelayanan kesehatan gigi dan laboratorium. Sarana pendukung administrasi seperti komputer dan internet masih belum lengkap dan harus segera dipenuhi. Sumber daya keuangan yang mendukung Puskesmas Sindar Raya sudah tersedia. Penelitian ini bertujuan untuk mengaanalisis pelaksanaan sistem Jaminan Kesehatan Nasional (JKN) di Puskesmas Sindar Raya Kabupaten Simalungun. Jenis penelitian yang digunakan dalam penelitian ini menggunakan pendekatan kualitatif dengan wawancara mendalam terhadap sumber informasi agar diketahui faktor pendukung dan penghambat pelaksanaan program Jaminan Kesehatan Nasional (JKN) di Puskesmas Sindar Raya. Hasil penelitian menunjukkan bahwa secara fragmentasi, struktur birokrasi sudah berjalan sesuai dengan tugas dan perannya masing-masing. Pelayanan kesehatan dalam JKN di lapangan dapat dilaksanakan karena tidak ada perbedaan mendasar dalam memberikan pelayanan kesehatan. Puskesmas Sindar Raya dalam upaya peningkatan pelayanan kesehatan agar lebih aktif agar mampu mengimplementasikan program JKN dengan maksimal.
\end{abstract}

Kata Kunci: Program JKN, Puskesmas Sindar Raya.

\section{ABSTRACT}

The Sindar Raya Community is largely a lower middle class society although there are still a smallpotion of the upper middle class. This type of research used in this study uses a Qualitative Approach with indepth interview with information sources so that known factors supporting and inhibiting the implementation of the Jaminan Kesehatan Nasional (JKN) program at Puskesmas Sindar Raya.The Human resources of the Puskesmas Sindar Raya are still lacking in quantity and quality. But in health services, there is no fundamental difference with service before JKN and the JKN era. The ability of resources administration is still not ready in implementing the JKN reporting format. Facilities and infrastructure are still lacking but can still maximize health services to the commnunity. Medical facilities that are still incompleteb are dental and laboratory health services. Administrative support facilities such as computers and the internet are still incomplete and must be fulfilled immediately. Financial resources that support the Puskesmas Sindar Raya are available. In Fragmentation, the bureaucratic structure has been running in accordance with their respective duties and roles. Health services in JKN in the field can be implemented because there are no fundamental diffrences in Providing health services. Puskesmas Sindar Raya in an effort to improve health services to be more active in order to be able to implement the JKN program to the maximum.

Keywords: JKN Program, Puskesmas Sindar Raya.

\section{PENDAHULUAN}

Salah satu hambatan utama bagi masyarakat untuk memperoleh pelayanan kesehatan adalah ketidak mampuan masyarakat dalam mengakses pelayanan kesehatan terutama keterbatasan biaya
(InfoAskes, 2010). Upaya yang tepat untuk mengatasi permasalahan tersebut adalah dengan asuransi/jaminan kesehatan. JKN adalah program pemerintah untuk masyarakat/rakyat dengan tujuan memberikan kepastian jaminan kesehatan yang 
menyeluruh bagi setiap rakyat Indonesia agar seluruh rakyat Indonesia dapat hidu psehat, produktif dan sejahtera (Naskah Akademik SJSN).

JKN mulai diterapkan pemerintah Indonesia sejak tanggal 1 Januari 2014. Sehingga penyelenggaraan program tersebut masih perlu diperhatikan pelaksanaannya oleh semua pihak. Pelaksanaan JKN ini menuntut penyedia pelayanan kesehatan termasuk puskesmas harus memiliki standard yang terukur sebagai penyedia pelayanan kesehatan. Puskesmas harus melalui proses kredensialing dengan standard yang telah ditetapkan, sehingga kapasitas puskesmas sebagai penyedia pelayanan kesehatan sesuai dengan standard (Kemenkes RI, 2013). JKN dilaksanakan dengan harapan tercovernya jaminan kesehatan seluruh masyarakat Indonesia yang sebelumnya tidak memiliki akses terhadap pelayanan kesehatan kemudian pada akhirnya mendapatkan pelayanan kesehatan yang maksimal. Namun, dalam pelaksanaannya masih ditemui permasalahan yang terjadi di lapangan. Untuk itu, peneliti mempertimbangkan perlu dilakukan penelitian tentang analisis pelaksanaan sistem Jaminan Kesehatan Nasional (JKN) di Puskesmas Sindar Raya Kabupaten Simalungun tersebut.

\section{METODE}

Metode penelitian yang digunakan dalam penelitian ini adalah Grounded Theory (GT) menggunakan pendekatan kualitatif dengan wawancara mendalam terhadap sumber informasi agar diketahui secara jelas dan lebih mendalam tentang pelaksanaan program JKN di Puskesmas Sindar Raya (Sugiyono, 2012). Metode GT ini digunakan karena data yang diambil berdasarkan pada fakta yang terjadi di lapangan. Informan dalam penelitian ini diambil secara purposive (bertujuan), yaitu Kepala Bidang Pelayanan Kesehatan Dinas Kesehatan Kabupaten Simalungun, Kepala Puskesmas Sindar Raya, Dokter umum diPuskesmas Sindar Raya, Bidan di Puskesmas Sindar Raya, Perawat di Puskesmas Sindar Raya, Apoteker di Puskesmas Sindar Raya, Pasien pengguna JKN diwilayah kerja Puskesmas Sindar Raya, Pasien non JKN diwilayah kerja Puskesmas Sindar Raya. Data yang dikumpulkan dalam penelitian adalah data primer dan data sekunder. Instrumen yang digunakan dalam penelitian ini adalah alat tulis dan alat perekam suara. Analisis data kualitatif dilakukan secara simultan dengan proses pengumpulan data, interpretasi data dan dibuat matriks untuk mempermudah dalam melihat data secara lebih sistematis (Miles and Huberman dalam Herdiansyah, 2012).

\section{HASIL DAN PEMBAHASAN \\ 3.1 Hasil}

Dari wawancara yang dilakukan kepada informan maka didapat informasi mengenai pelaksanaan program sistem Jaminan Kesehatan Nasional (JKN) Di Puskesmas Pamatang Sindar Raya Kabupaten Simalungun Tahun 2017, maka di dapat hasil sebagai berikut:

\section{Karakteristik Informan}

Informan dalam penelitian ini berjumlah 7 orang yaitu Kepala Puskesmas Sindar Raya, Dokter Umum di Puskesmas Sindar Raya, koordinator bidan di Puskesmas Sindar Raya, koordinator perawat di Puskesmas Sindar Raya, apoteker di Puskesmas Sindar Raya, pasien pengguna JKN dan pasien non JKN di wilayah kerja Puskesmas Sindar Raya.

\section{Hasil Wawancara Pelaksanaan Program JKN di PuskesmasSindar Raya}

1. Wawancara mengenai pelayanan kesehatan sebelum dan setelah berlakunya program JKN

Bahwa tidak ada perbedaan yang menonjol dalam pelaksanaan pelayanan kesehatan dalam era JKN saat ini yang diberikan dari Puskesmas Sindar Raya dengan sebelum diberlakukannya program JKN. Hanya saja sedikit perbedaan terletak pada sistem pembiayaan dan cakupan jaminan kesehatan masyarakatnya. UKM dan UKP tetap dijalankan hingga saat ini oleh Puskesmas Sindar Raya. Seluruh pasien, baik pasien peserta JKN maupun bukan peserta JKN tetap diberikan pelayanan kesehatan sesuai dengan kebutuhan pasien.

2. Wawancara mengenai kebijakan mengenai program JKN

Diketahui bahwa kebijakan peraturan mengenai pelayanan kesehatan dalam 
era JKN yang diketahui oleh para informan antara lain Undang-Undang No. 40 Tahun 2004 tentang SJSN, Undang-Undang No. 24 Tahun 2011 tentang BPJS, Peraturan Presiden No. 111 Tahun 2013 tentang Jaminan Kesehatan, lalu terdapat dalam Peraturan Menteri Kesehatan No.71 Tahun 2013 tentang Pelayanan Kesehatan pada Jaminan Kesehatan Nasional. Mengenai pengelolaan dana kapitasi JKN pada FKTP diatur dalam Peraturan Presiden No.32 Tahun 2014. BPJS juga menerbitkan Peraturan BPJS No.1 Tahun 2014 tentang Penyelenggaraan Jaminan Kesehatan.

3. Wawancara mengenai sistem pembiayaan untuk pelayanan kesehatan sebelum dan setelah berlakunya JKN

Diketahui bahwa sebelum JKN berjalan, dana kegiatan UKM dan UKP bersumber dari dana BOK. Setelah JKN berjalan, dana kegiatan UKM tetap bersumber dari BOK sementara dana untuk kegiatan UKP bersumber dari dana kapitasi JKN. Sistem pembiayaan di FKTP seperti puskesmas dibayarkan secara kapitasi oleh BPJS sesuai dengan jumlah peserta terdaftar JKN di FKTP tersebut. Pengelolaan dan pemanfaatan dana kapitasi JKN diatur dalam Perpres No. 32 Tahun 2014.

4. Wawancara mengenai jumlah tenaga kesehatan di Puskesmas Sindar Raya Diketahui bahwa menurut informan tenaga kesehatan di Puskesmas Sindar Raya masih kurang memadai secara kualitas dan kuantitas. Belum lagi tidak tersedianya dokter gigi, padahal pelayanan kesehatan gigi merupakan salah satu pelayanan kesehatan dalam program JKN. Hal ini membuat tidak maksimalnya pelayanan kesehatan dalam era JKN di Puskesmas Sindar Raya.

5. Wawancara mengenai sarana dan prasarana di puskesmas untuk menjalankan program JKN secara maksimal

Diketahui bahwa menurut para informan sarana dan prasarana sudah terbilang cukup, hanya informan mengeluhkan tidak adanya ruangan laboratorium dan kendaraan. Kendaraan seperti mobil dan sepeda motor sangat diperlukan, karena mengingat jarak yang harus ditempuh termasuk jauh sedangkan kendaraan yang ada terbatas. Karena kendaraan pribadi tenaga kesehatan tidak selalu ada untuk digunakan. Dalam masalah media sosialisasi JKN masih sangat kurang sehingga masyarakat sulit memahami mekanisme JKN tersebut.

6. Wawancara mengenai hambatan dalam menjalankan program JKN baik internal maupun eksternal yang dihadapi oleh Puskesmas Sindar Raya

Diketahui bahwa tantangan internal yang dihadapi oleh Puskesmas Sindar Raya adalah kurangnya jumlah tenaga kesehatan dan kualitas tenaga kesehatannya, sehingga pelayanan kesehatan menjadi tidak maksimal. Tantangan eksternal yang dihadapi Puskesmas Sindar Raya datang dari pasien atau masyarakat yang pengetahuannya sangat kurang tentang mekanisme JKN, terutama dalam sistem rujukan. Banyak masyarakat yang mengeluh mengenai rujukan yang tidak bisa ganda padahal jelas sudah bahwa dalam JKN tidak ada rujukan ganda. Rujukan yang ganda adalah dalam satu bulan pasien pengguna JKN tidak boleh meminta dua kali rujukan dengan penyakit yang sama.

7. Wawancara mengenai strategi yang dilakukan dalam menangani kendala internal maupun eksternal yang dihadapi oleh Puskesmas Sindar Raya

Diketahui bahwa strategi yang dilakukan oleh Puskesmas Sindar Raya dalam menghadapi tantangan internal adalah dengan mengajukan penambahan jumlah dokter di puskesmas. Dari segi kualitas/skill sebisa mungkin tenaga kesehatan di puskesmas selalu mengikuti pelatihan yang dilakukan Dinas Kesehatan untuk meningkatkan kualitas tenaga kesehatan sendiri. Sementara itu, strategi untuk menghadapi hambatan eksternal puskesmas sebisa mungkin tenaga kesehatan memberikan pengetahuan tentang mekanisme JKN kepada masyarakat.

8. Wawancara mengenai Saran untuk peningkatan pelayanan kesehatan dalam era JKN 
Diketahui bahwa saran-saran yang diberikan oleh para informan adalah pemenuhan kekurangan dokter di puskesmas, adakan pelatihan-pelatihan, perbanyak lagi media-media sosialisasi JKN yang lebih beragam dan mudah dimengerti oleh masyarakat dan pemenuhan obat-obatan yang masih kurang di puskesmas

9. Wawancara mengenai tentang petugas kesehatan yang memberikan pengetahuan tentang mekanisme JKN Diketahui bahwa tenaga kesehatan hanya memberikan pengetahuan tentang mekanisme JKN hanya jika ditanyakan saja oleh pasien, kalau tidak ditanyakan petugas kesehatan tidak memberikan pengetahuan. Masyarakat mengharapkan adanya media-media sosialisasi tentang JKN agar pasien sendiri bisa membaca dan mengerti tanpa harus berulang kali bertanya kepada petugas kesehatan.

10. Wawancara mengenai kepuasan pasien dengan pelayanan kesehatan di Puskesmas Sindar Raya sebelum dan setelah era JKN

Diketahui bahwa pasien yang memanfaatkan pelayanan kesehatan di Puskesmas Sindar Raya masih belum puas terhadap pelayanan di Puskesmas Sindar Raya. Mereka mengeluhkan masalah dokter yang cuma ada satu dan jarang datang, belum lagi masalah obat yang tidak ada stok sehingga harus beli di luar (apotik). Masyarakat mengharapkan adanya penambahan dokter dan dokter gigi, agar pelayanan kesehatan di Puskesmas Sindar Raya dapat berjalan dengan maksimal.

\subsection{Pembahasan \\ Kebijakan}

Berdasarkan hasil penelitian didapatkan bahwa kebijakan dalam penerapan JKN sudah ada. Aspek ini meliputi fragmentasi, tugas pokok dan fungsi. Dalam konteks fragmentasi, tugas pokok dan fungsi, struktur birokrasi sudah berjalan sesuai dengan tugas dan perannya masing-masing. Sedangkan dengan BPJS kesehatan fragmentasi yang terbentuk tidak sampai menimbulkan struktur birokrasi yang berjenjang, sebab tidak ada garis instruksi antara BPJS dengan puskesmas. Instruksi yang terbangun sesuai dengan kesepakatan antara BPJS dengan puskesmas sebagai penyedia pelayanan kesehatan tingkat pertama.

\section{Tenaga Kesehatan}

Tenaga kesehatan di Puskesmas Sindar Raya tergolong masih kurang dari segi kuantitas. Kondisi ini terjadi karena kurangnya dokter umum dan dokter gigi di Puskesmas Sindar Raya. Dinas Kesehatan Kabupaten Simalungun sendiri menyadari bahwa belum meratanya penyebaran dokter umum dan dokter gigi di puskesmaspuskesmas di Kabupaten Simalungun. Tidak tersedianya dokter gigi di Puskesmas Sindar Raya merupakan salah satu masalah yang dihadapi, karena pelayanan gigi merupakan salah satu bentuk pelayanan yang tersedia dalam program JKN. Kondisi ini dapat menghambat pelaksanaan program JKN di puskesmas karena akan berpengaruh kepada tidak maksimalnya pelayanan kesehatan di Puskesmas Sindar Raya. Ketersediaan jumlah tenaga kesehatan juga dilihat secara kualitas, tidak adanya perbedaan dalam pelayanan kesehatan sebelum JKN membuat tenaga kesehatan tidak memerlukan spesifikasi khusus yang lebih kompleks dalam memberikan pelayanan kesehatan di tingkat puskesmas.

Permasalahan tenaga kesehatan secara kualitas terlihat dari ketidakmampuan tenaga kesehatan di puskesmas dalam mengirimkan laporan secara tepat waktu. Permasalahan lain yang muncul adalah pada pelayanan pendukung yang bersifat administratif. Permasalahan ini muncul karena kurang intensifnya pengarahan sistem pelaporan ke tingkat puskesmas serta masih kurangnya sarana dan prasarana pendukung.

Berkaitan dengan kualitas tenaga kesehatan intinya adalah proses pengarahan dan sosialisasi yang seharusnya lebih diintensifkan kepada petugas puskesmas. Kemudian penentuan pelaksana juga haruslah orang yang tepat dan konsisten agar keberlanjutan proses sosialisasi juga tetap terjaga. Selain itu hal yang juga penting diperhatikan adalah sosialisasi kepada masyarakat umum mengenai mekanisme pelaksanaan JKN. 


\section{Pendanaan}

Dalam konteks ini maka pembiayaan puskesmas untuk UKP didukung oleh dana kapitasi dari BPJS Kesehatan.BPJS Kesehatan melakukan pembayaran dana kapitasi kepada FKTP milik Pemerintah Daerah, didasarkan pada jumlah peserta BPJS yang terdaftar di puskesmas. Dana kapitasi dibayarkan langsung oleh BPJS Kesehatan kepada Bendaharawan Dana Kapitasi JKN pada puskesmas, di Puskesmas Sindar Raya sendiri belum ada bendaharawan dana kapitasi maka yang menerimanya adalah Kepala Puskesmas Sindar Raya.

\section{Sarana Kesehatan}

Sarana adalah seluruh bahan, peralatan serta fasilitas yang digunakan dalam pelaksanaan suatu program. Dalam mendukung pelaksanaan program JKN di puskesmas saranayang dibutuhkan adalah ruangan, obatyang lengkap dan media penyuluhan/sosialisasi JKN. Di Puskesmas Sindar Raya, ruangan untuk laboratorium masih belum tersedia, hal ini sangat mengganggu pelaksanaan pelayanan kesehatan di Puskesmas Sindar Raya. Dari hasil penelitian, kepala puskesmas menyatakan bahwa hal ini sudah diajukan tinggal menunggu hasil dari Dinas Kesehatan Kabupaten Simalungun kapan akan dibangun di Puskesmas Sindar Raya tersebut.

Pemerintah daerah seharusnya merencanakan kebutuhan fasilitas ini jauh sebelum penerapan JKN sehingga pelaksanaannya akan bisa lebih maksimal. Perencanaan sektor kesehatan dipengaruhi oleh adanya prioritas sektor lain non sektor kesehatan sehingga mengurangi alokasi pembiayaan untuk sektor kesehatan khususnya yang dapat mendukung pelayanan kesehatan dalam program JKN. Berdasarkan hasil penelitian masalah lain yang muncul dalam sarana dan prasarana ini adalah ketersediaan obat juga masih belum lengkap. Dari yang dituturkan oleh apoteker bahwa obat-obatan yang ada di puskesmas masih kurang sehingga terkadang pasien harus membeli sendiri obat di luar puskesmas.

Satu lagi masalah yang timbul dalam sarana kesehatan yakni Puskesmas Sindar Raya masih kekurangan sarana pendukung umum yaitu komputer dan jaringan internet. Sarana ini merupakan sarana pendukung umum yang dibutuhkan dalam pelaporan pelayanan kesehatan kepada BPJS setiap harinya. Kekurangan sarana pendukung ini juga berdampak terhadap pelaporan online setiap harinya.

\section{Proses (process)}

Pelaksanaan pelayanan kesehatan pada masing-masing upaya kesehatan di Puskesmas Sindar Raya telah memiliki Plan of Action (POA) pada setiap awal tahun. Selain itu kegiatan promotif seperti penyuluhan kesehatan, dilaksanakan tidak selalu sesuai dengan program yang dipegang oleh masing-masing tenaga kesehatan di Puskesmas Sindar Raya. Pada saat terjadwal harus turun ke lapangan untuk menyuluh masyarakat, tenaga kesehatan program manapun yang sedang tidak terlalu sibuk di puskesmas diharuskan turun ke lapangan. Puskesmas Sindar Raya selalu mengupayakan agar kegiatan-kegiatan yang telah disusun dalam POA dapat dilaksanakan sesuai rencana. Ada beberapa kendala yang dihadapi tenaga kesehatan di Puskesmas Sindar Raya dalam melaksanakan UKM, yaitu jadwal yang tertera di POA terkadang bertepatan dengan kegiatan yang diadakan Dinas Kesehatan Kabupaten Simalungun di mana tenaga kesehatan puskesmas diharapkan hadir, sehingga pelaksanaan kegiatan harus diundur.

Selain itu, yang menjadi kendala dalam pelaksanaan upaya kesehatan masyarakat bagi tenaga kesehatan adalah daerah yang hendak dituju cukup jauh dan sulit dijangkau. Akses kendaraan yang sulit untuk sampai ke tempat tinggal masyarakat guna mengadakan kegiatan posyandu dan penyuluhan. Seringnya pasien yang tidak terdaftar peserta JKN di Puskesmas Sindar Raya berkunjung untuk berobat di Puskesmas Sindar Raya juga menjadi kendala bagi tenaga kesehatan. Hal ini menandakan bahwa masyarakat tidak terlalu paham dengan aturan JKN. Bisa juga berarti sosialisasi mengenai JKN yang masih kurang.

\section{Keluaran (Output)}

Penyelenggaraan upaya kesehatan diutamakan pada upaya pencegahan dan peningkatan kesehatan tanpa mengabaikan upaya pengobatan dan pemulihan kesehatan. Penyelenggaraan upaya keseh atan dilakukan 
dengan prinsip kemitraan antara pemerintah, masyarakat dan swasta. Menghadapi tantangan dan tuntutan pembangunan kesehatan, perlu dilakukan reorientasi upaya kesehatan yaitu berorientasi pada desentralisasi, globalisasi, perubahan epidemiologi dan menghadapi keadaan bencana.

Pelayanan kesehatan yang telah dilakukan oleh tenaga kesehatan di Puskesmas Sindar Raya untuk meningkatkan derajat kesehatan masyarakat khususnya di Sindar Raya tidak terlalu berbeda dengan sebelum berlakunya JKN, antara lain adalah meningkatkan pelayanan Kesehatan Ibu dan Anak (KIA), imunisasi, pemantauan gizi buruk di posyandu, peningkatan pengetahuan ibu hamil, kader kesehatan dan sosialisasi keluarga sadar gizi. Untuk kegiatan penyuluhan selalu dibuat laporan untuk dilaporkan ke Dinas Kesehatan Kabupaten Simalungun.

Berdasarkan keluaran yang diinginkan yakni meningkatnya pemanfaatan pelayanan kesehatan di Puskesmas Sindar Raya, maka Puskesmas Sindar Raya harus mampu memberikan pelayanan yang maksimal sehingga masyarakat mau memanfaatkan pelayanan kesehatan di Puskesmas Sindar Raya. Kepada Dinas Kesehatan Kabupaten Simalungun harus segera memenuhi kekurangan jumlah dokter umum dan dokter gigi di Puskesmas Sindar Raya, karena hal ini yang banyak dikeluhkan oleh masyarakat yang ingin memanfaatkan pelayanan kesehatan di puskesmas.

Satu lagi keluaran yang diinginkan yakni tercovernya masyarakat Sindar Raya dalam JKN maka menurut penuturan Kepala Puskesmas Sindar Raya sudah 85\% masyarakat Sindar Raya yang terdaftar dalam JKN. Jumlah ini sudah terbilang sangat memuaskan karena hanya sebagian kecil lagi masyarakat yang belum tercover. Hal ini akan terus diusahakan oleh Puskesmas Sindar Raya sehingga seluruh masyarakat Sindar Raya tercover dalam JKN sehingga masyarakat mendapatkan pelayanan kesehatan yang maksimal tanpa terbebani masalah biaya.

\section{KESIMPULAN}

1. Sumber daya manusia Puskesmas Sindar Raya dalam menjalankan program JKN tergolong masih kurang secara kuantitas dan kualitas. Tidak meratanya penyebaran dokter umum dan dokter gigi ke puskesmas-puskesmas menjadi salah satu masalah kurangnya sumber daya manusia di Puskesmas Sindar Raya. Namun dalam pelayanan kesehatan, tidak ada perbedaan secara mendasar dengan pelayanan sebelum JKN dengan era JKN sekarang ini.

2. Kemampuan administrasi sumber daya manusia di Puskesmas Sindar Raya masih kurang siap dalam menerapkan format pelaporan JKN.

3. Sarana dan prasarana Puskesmas Sindar Raya masih tergolong kurang dalam memberikan pelayanan kesehatan. Walaupun masih tergolong kurang tetapi puskesmas masih bisa memaksimalkan pelayanan kesehatan kepada masyarakat.

4. Sarana medis yang masih belum lengkap adalah pelayanan kesehatan gigi dan laboratorium. Dokter gigi yang tidak ada serta ruang laboratorium yang tidak ada sehingga tidak bisa maksimal dalam pelayanan gigi dan laboratorium.

5. Sarana pendukung administrasi seperti komputer dan internet masih belum lengkap dan harus segera dipenuhi.

6. Sumber daya keuangan yang mendukung Puskesmas Sindar Raya sudah tersedia. Akan tetapi system administrasi birokrasi dalam pemanfaatan keuangan masih belum maksimal dalam mendukung pemanfaatan sumber keuangan tersebut, akses petugas terhadap keuangan masih melalui sistem birokrasi yang menyita waktu sehingga dapat menghambat operasionalisasi puskesmas.

7. Struktur birokrasi dan kebijakan dalam penerapan JKN sudah jelas. Secara fragmentasi, struktur birokrasi sudah berjalan sesuai dengan tugas dan perannya masing-masing. Sedangkan standard operasional dalam pelaksanaan JKN ini juga sudah jelas. Berbagai standar operasional dalam pelayanan kesehatan sudah diterbitkan sebagai 
panduan.

8. Komitmen sebagai salah satu bentuk disposisi dalam menjalankan kebijakan JKN sudah jelas. Keseluruhan stakeholder sepakat dan berkomitmen untuk memperbaiki permasalahan yang ada dalam pelaksanaan JKN diwilayah kerja Dinas Kesehatan Kabupaten Simalungun.

9. Pelayanan kesehatan dalam JKN di lapangan dapat dilaksanakan karena tidak ada perbedaan mendasar dalam memberikan pelayanan kesehatan, permasalahan yang banyak muncul dalam pelaksanaan JKN di Puskesmas Sindar Raya yaitu masih ada permasalahan dalam mensinkronkan kepesertaan dengan program jaminan kesehatan yang ada sebelumnya serta permasalahan sosialisasi yang masih kurang kepada masyarakat dalam prosedural pelayanan rujukan.

\section{REFERENCES}

Asri, Anggi. 2014. Analisis Pelaksanaan Pelayanan Promotif dan Preventif dalam Era Jaminan Kesehatan Nasional di Puskesmas Belawan Tahun 2014. Skripsi. Medan: Universitas Sumatera Utara.

Badan Penyelenggara Jaminan Sosial. 2014. Peraturan No.1 Tahun 201 tentang Penyelenggaraan Jaminan Kesehatan Nasional. Jakarta.

Darmawi, Herman. 2000. Manajemen Asuransi. Jakarta: BumiAksara.

EffendiF., Makhfudli. 2009. Keperawatan Kesehatan Komunitas. Jakarta: Salemba Medika.

Gunawan, Roni. 2014. Analisis Kesiapan Dinas Kesehatan Kota Medan dalam Implementasi Kebijakan Jaminan Kesehatan Nasioanal di Puskesmas. Tesis. Medan: Universitas SumateraUtara.

Helmchen, Lorens. 2008. Beyond Health Insurance: Public Policy to Improve Health. Bingley. Emerald Group Publishing Limited.

Herdiansyah, Haris. 2012. Metodologi Penelitian Kualitatif untuk Ilmu-Ilmu Sosial. Jakarta: Salemba Humanika.

Ilyas, Yaslis. 2006. Determinan Distribusi Dokter Spesialis di Kota/Kabupaten

Indonesia. Jurnal Manajemen

Pelayanan Kesehatan, Volume: 9.

Kementerian Kesehatan Republik Indonesia. 2011. Laporan Akhir Riset Fasilitas Kesehatan Puskesmas Tahun 2011. Jakarta: Kementerian Kesehatan Republik Indonesia Tahun2013.

Kementerian Kesehatan Republik Indonesia. 2013. Buku Pegangan Sosialisasi Jaminan Kesehatan Nasional (JKN) dalam Sistem Jaminan Sosial Nasional. Jakarta: Kementerian Kesehatan Republik Indonesia.

Kementerian Kesehatan Republik Indonesia. 2013. Peraturan Menteri Kesehatan No.71 Tahun 2013 Tentang Pelayanan Kesehatan pada Jaminan Kesehatan Nasional. Jakarta: Kementerian Kesehatan Republik Indonesia.

Kementerian Kesehatan Republik Indonesia. 2014. Jaminan Kesehatan Nasional. Jakarta: Kementerian Kesehatan Republik Indonesia.

Kementerian Kesehatan Republik Indonesia. . 2014. Peraturan Menteri Kesehatan Republik Indonesia Nomor 75 Tahun 2014 tentang Puskesmas. Jakarta: Kementerian Kesehatan Republik Indonesia.

Kementrian Koordinator Kesejahteraan Rakyat. 2012. Peta Jalan Menuju Jaminan Kesehatan Nasional 20122019. Jakarta: Kementrian Koordinator Kesejahteraan Rakyat.

Lubis, Ade Fatma. 2009. Ekonomi Kesehatan. Medan: USU Press.

Manggala,Wahyu. 2014. Analisis Implementasi Kebijakan Jaminan Kesehatan Nasional (JKN) di Rumah Sakit Umum Kota Tangerang Selatan Tahun 2014. Skripsi. Jakarta: Universitas Islam Negeri Syarif Hidayatullah.

Moleong, Lexi J. 2005. Metodologi Penelitian Kualitatif. Bandung: Remaja Rosdakarya.

Muninjaya, A. A.Gde. 2004. Manajemen Kesehatan. Jakarta: EGC.

Murtika, I Ketut. 2004. Hukum Asuransi Indonesia. Jakarta:Rineka Cipta.

Peraturan Presiden. 2013. Peraturan Presiden Republik Indonesia Nomor 12 Tahun 2013 tentang Jaminan Kesehatan. Jakarta. 
Peraturan Presiden. 2014. Peraturan Presiden Republik Indonesia Nomor 32 Tahun 2014 tentang Pengelolaan dan Pemanfaatan Dana Kapitasi pada Fasilitas Kesehatan Tingkat Pertama (FTKP) Milik Pemerintah Daerah. Jakarta.

Profil Kesehatan Puskesmas Sawit Seberang Tahun 2013.

Purwoko, Bambang. 1999. Jaminan Sosial dan Sistem Penyelenggaraannya: Pandangan dan Gagasan. Jakarta: Meganet Dutatama.

Republik Indonesia. 1945. Undang-Undang Dasar Negara Republik Indonesia Tahun1945. Jakarta.

Soekamto, Hasbullah Thabrany, dan Bambang Purwoko. 2006. Reformasi Sistem Jaminan Sosial di Indonesia [Undang-Undang Nomor 40 Tahun 2004 tentang Sistem Jaminan Sosial Nasional Pasca Putusan Mahkamah Konstitusi RI]. Jakarta: Kementerian Koordinator Bidang Kesejahteraan Rakyat RI Bekerjasama dengan German Technical Cooperation ( GTZ).
Sugiyono. 2012. Metode Penelitian Kombinasi (Mix Methode). Bandung: Alfabeta.

Sulastomo. 2000. Manajemen Kesehatan. Jakarta: Gramedia PustakaUtama.

Thabrany, H. 2011. Asuransi Kesehatan Nasional. Jakarta: PAMJAKI.

Trihono. 2005. Manajemen Puskesmas Berbasis Paradigma Sehat. Jakarta: Sagung Seto.

Undang-Undang Republik Indonesia Nomor 2 Tahun 1992 tentang Usaha Perasuransian.

Undang-Undang Republik Indonesia Nomor 40 Tahun 2004 tentang Sistem Jaminan Sosial Nasional.

Undang-Undang Republik Indonesia Nomor 36 Tahun 2009 Tentang Kesehatan.

Undang-Undang Republik Indonesia Nomor 24 Tahun 2011 tentang Badan Penyelenggara Jaminan Sosial.

USAID. 2010. Taking The Pulse of Policy: The Policy Implementation Assessmenttool. Washington DC: USAID. 